\title{
DIGITAL TECHNOLOGIES IN HIGHER AND SECONDARY-SPECIAL EDUCATION: BLOCKCHAININ TARGET TRAINING OF INNOVATIVE PERSONNEL
}

\author{
Kasimova Nargiza Sabitdjanovna, $\mathrm{PhD}$, Tashkent institute of finance \\ Tashkent, Uzbekistan, kasimovanargiz@,gmail.com \\ Ismailova Nilufar Sabitdjanovna, $\mathrm{PhD}$, Tashkent state university of economics \\ Tashkent, Uzbekistan, nilyufar77@mail.ru
}

Abstract. The development of digital technology has lead to new opportunities for the organization of the educational process. The absence of scientifically - based advanced research methodology development of higher and secondary special education does not permit effective use of all the possibilities that digital technologies offer today. The most promising are the possibilities of working with big data (BigData); deep learning in a professional environment (Deep Learning); cloud and blockchain technologies (Cloud). It is likely that in the context of the development of virtual machines (VR), a number of previously unexplored educational opportunities will be implemented, which will complement the range of previously known teaching methods. Thus, modern didactics of vocational education for the successful realization of digital technology opportunities should be focused on the formation of a professional information culture for graduates. Formation of the methodology of smart didactics allowsthe expanding of the range of classification for approaches to teaching methods. Training specialists in terms of implementing the blockchain will allow the integration of the interests of employers, learners and the state, making it more open and focused. A special feature of preparation for the blockchain is the possibility of targeted training, for which a student in the first year knows about his future workplace and also an employer knows about his future specialist andis ready to provide the necessary practice on promising technologies.

Keywords: digital technologies, higher and vocational education, student's personality, vocational education didactics, professional culture, blockchain, smart didactics, targeted training of specialists.

\section{Introduction}

Digital technology is actively enteringall areas of life. The accelerators of these processes formed the economy and the banking sector. The availability of information resources to all categories of citizens - from young children to retirees - forms the idea that information technologies can solve absolutely all the problems that worry modern society. Moreover, the robotization of production and processes, for example in the banking sector, raised the question of competition between robots and employees.

With the absolute benefit of the implemented technologies based on the use of "numbers", issues related to ethics, personal data protection, legal aspects of competition between robots and employees of organizations and so on are becoming more prominent. Oneneeds to understand the place and role of digital technologies in modern education which should be reflected in modern research in 
the field of methodology and the didactics of higher and specialized secondary education.

The purpose of this study is to identify priority areas for the development of the educational process based on the analysis of digital technology opportunities, based on the hypothesis that they need to be scientifically based on the work of organizations of higher and specialized secondary education, based on the cultural approach developed by science.

Materials and research methods. The following were used as research materials: legal documents defining the priority development of the educational system in the Republic of Uzbekistan; information resources and the technologies of educational and scientific organizations; the practice of scientific and pedagogical workers of universities and college teachers. The research methods were the study and analysis of legal documentation, established practice, systematization and generalization in building conclusions relevant to the formation of a scientifically - based approach to the introduction of digital technologies into the system of higher and specialized secondary education.

The swiftness with which the educational system has become immersed in digital technology today is not just amazing, it provides a basis for serious analysis and pedagogical substantiation of much of what is offered today in the information space. It is important that in recent years there has not appeared a single state project or significant psychological study of the problems of "digitalization" of education and its influence on the formation of personality. At the same time, the importance of the impact of the Internet environment on youth is noted in the reports of the government, modern media, in discussions of the teaching community, research of graduate students, and deputies.

This is most acute in the vocational education system, when the information space is replete with all sorts of communities that are in the "reference" group of students, especially in colleges. The absence of a psychologically based informational educational policy provides for spontaneous development, and sometimes not spontaneous, but purposeful, in the interests of various groups and communities, the formation of the mentality of the younger generation.

It should be noted that the state has been preoccupied with the introduction of digital technologies in to all spheres: industry, economy, banking, etc. In state structures, deputy heads of digital development have been hired. Total activation in the direction of digitalization occurs in all business structures.

Today's "offensive" of digital technologies in all areas, especially where an economic effect is found, is supported at all levels. Immersion of the younger generation in the information environment is necessary. This is not disputed by anyone. The dynamics of the processes taking place in the economy require an active position of the educational community in analyzing and developing proposals for the development of a system of higher and specialized secondary education in the context of the digital transformation of the economy.

The current situation is partly due to the fact that in the conditions of the information society, it is simply impossible not to use digital technologies, since we wouldlag hopelessly behind. But it is also necessary to move forward very 
carefully, because "digitalization" only as a spontaneously developing fashion trend can have a negative impact on the formation of the identity of the student. What needs to be done today for the scientifically based introduction of digital technologies in personnel training? In general education, the driver of all processes is the universities. The support from the Ministry of Higher and Secondary Special Education allowed us to identify a number of priorities in the development of the educational process. Much of the proposed educational technology is really relevant and is able to completely build a new learning process. However, how to build an educational technology based on the use of the "digit" to ensure its effectiveness and the absence of harm to the trainees?

The stimulation of teachers using digital technologies, as is done in Uzbekistan, is certainly an important aspect. That is, there must be motivation for the teacher. For the students, this is also interesting, even fascinating. What's next? Should a robot talk instead of a teacher? Should it explain if the student is at a loss? Another aspect: the student reads everything on the screen. Without going into the analysis of the content of educational materials (this is a separate and very important topic), it should be noted that after a certain time (each child has its own limit of patience) this can cause fatigue and rejection. On what research can we rely in order to be confident in the reasonable application of the computer variant?

Imagine that a schoolboy announces that he will never forget his first teacher - the "online platform" that taught him to read, write, love the nation ... And how the student's idea of his teacher, a real professional who wants to imitate, will be formed - " Am I the perfect professional if he hasn't seen him? I can argue that it will not come to this, we must somehow combine these technologies, etc. Let's give an example: working as a manager. the laboratory of labor and vocational training of schools, I participated in the experimental verification of the first textbook on labor training. The statistics obtained showed that in those classes where the textbook was not used, the performance was higher than in the experimental classes. The lack of understanding of the didactic function of a textbook in teacher training led to a completely opposite, negative effect. It took the training of teachers, where the error was repaired. Who among teachers today can confidently vench for the didactic function of a particular digital technology used? That is, a lack of understanding of the didactic function of e-learning tools can lead to a similar result. The introduction of digital technologies, the use of their didactic possibilities should be pedagogically justified from the standpoint of problem solving, training, educating and developing the personality of both the student and the student. Moreover, taking into account age-related features in connection with the introduction of digital technologies in education should be implemented both in the formulation of the educational goal and in the choice of technology and methods of work of the teacher with the students. It is possible to continue such an analysis of what is happening further, only this does not make sense, since the process is running and one should wait for the results first.

It should be noted that graduates of schools for which e-learning has become an integral part of the development of the educational program will come to 
educational institutions of higher education, which should be ready to work with this category of students.

Higher education has taken a number of very important steps in this direction, in particular, using open online platforms for students to access information resources, training and testing, which can be taken into account in the results of a specialized university session.

In the secondary education system, the situation, at first glance, is simpler. However, the requirements for the implementation of practice-oriented training are fairly strictly regulated and it is possible to form the required competencies of college students only with a very reasonable combination of electronic and practical training. The demonstration exam is an exemplary process that allows you to quickly and objectively assess the level of practical training of a graduate. That is, without a didactic justification, the use of digital technologies in the pedagogical practice of teachers of higher and specialized secondary education is very difficult. Unfortunately, the process of their implementation occurs quite spontaneously: ideas arise that they immediately try to implement without any psychological and pedagogical analysis.

Many of the professionals involved in the introduction of digital technologies in education today are not familiar with pedagogy, but are wellversed in information and technical systems. For this category of workers programmers and engineers - elementary psychological and pedagogical training is important, knowledge of the results of scientific research in the field of psychology, pedagogy, and medicine, primarily from the standpoint of introducing digital technologies.

The basis of building the educational process in organizations of higher and specialized secondary education are the requirements of educational and professional standards. The competence-based approach is not able to fully identify ways to solve the problem of introducing digital technologies in education. Competent is the same thing as beautiful. Try to find criteria that can assess beauty or competence! The main focus on the formation of universal competencies that allow the graduate to work in a team, be communicative, etc., cannot be achieved without a good knowledge of professional knowledge and skills. It is a professional joint project activity that will enable students to master the competencies that can be attributed to universal ones. In practice, today, declaring the readiness and ability of graduates to perform certain competencies, teachers appeal to knowledge and skills that are more comprehensible for the organization of the educational process.

Today's bachelor - a graduate who owns certain standards of competence - is ready and capable of many things, but he must be taught what exactly to do in the workplace. This is currently happening with university graduates. Reducing the burden on lecture work and its transfer to students' independent study of material in the mode of working with an electronic teaching and methodical complex becomes an alternative to the traditionally established university practice. The course, which is compressed to educational programs and the most primitive 
version of using digital technologies using electronic CMDs, "almost" works because it takes less time to master and control via testing.

In this context, the issue of vocational education is important. Based on the work of LS Vygotsky, it is necessary to pay attention to the significance that was given in his research to the cultural approach. Culture - personal, professional, informational, etc. - is the link between the individual and the activities performed by him. Following this, as well as through research in psychological and pedagogical science, it is possible and necessary to build a methodology for the formation of the professional culture of the younger generation as an important goal of innovative training in the system of higher and secondary specialized education. This will allow us not only to understand how the process of creation of the information professional and educational space of Uzbekistan should occur, but also how the educational process should be built using digital technologies. Information culture of the individual, as part of the personal and professional culture of a specialist, is the goal of introducing digital technologies. This is a serious methodological mistake by many professionals who have made digital technology an end in itself in the educational process.

That is why the construction of modern didactic vocational education should be based on a cultural approach and reflect the implementation of the main tasks of the formation of culture in the educational process. The formation of a culture of professional activity, based on the capabilities of digital technologies, allows us to identify the main components that can be reflected in the content and technology of the educational process: knowledge, skills, personal attitudes and necessary personal qualities to perform a specific type of professional activity. If knowledge and skills are formed in learning activities, then personal attitudes and the development of certain important qualities are formed in the experience of professional and practical activities. It is the experience of performing professionally important tasks that should regulate professional standards, and not, as at present competencies. Knowledge and skills can be identified in the educational standard, they can be checked.These moments in our education system are worked out quite well. It is very difficult to describe requirements in standards from the point of view of competencies, and even more so to evaluate them in the educational process. This is precisely what is important in the development of the educational standard discussed today in the new generation (if we talk about professional education). Importantly, it notes the role of knowledge and the generation of experience among students. Indeed, the standard sets the requirements for the graduate, and we are well aware that the designated requirements in the form of professional functions and competencies performed by a future graduate determine the content of training, as well as being related to the educational technology being created. It is already possible to set requirements for the level of knowledge and experience in solving certain professional tasks using digital technologies, which to some extent corresponds to the goal of developing a graduate's professional culture.

Thus, digital technologies make it possible to focus the educational process not just on meeting the requirements of a professional and educational standard, 
but on shaping the professional culture of a future specialist, striving for continuous self-improvement through information services and technologies.

Competency as a concept should remain at the level of professional discussions and characterize training in general, reflecting a descriptive model of readiness and ability to perform certain types of activities. It is important to note that understanding the purpose of higher and secondary special education such as the development of the personal, professional and informational culture of a specialist, where digital technologies act as a powerful means for intellectual support and support of the educational process, provides an opportunity to address the development of the didactics of vocational education.

Modern didactics of vocational education for the successful implementation of digital technology should be focused on the formation of the professional culture of the graduate. Therefore, I would like to draw attention to one of the most important aspects of the problem of introducing digital technologies - didactic, since information technologies allow the student to adapt the personality characteristics to the specifics of the discipline studied - its conceptual complexity, abstractness in the study of electrical, hydraulic, etc. schemes Misunderstanding and lack of support for the laws and didactic principles of the organization of the educational process do not allow the effective use of digital resources in the educational process. The development of the educational process on the basis of a cultural approach will make it possible to identify the most important areas of the use of digital technologies and will make it possible, on the one hand, to more fully reveal their potential in the educational process, and on the other, not to harm the personality of the student.

Based on the fact that information technologies are currently being provided, the most promising for implementation in educational activities are the possibilities of working with big data (BigData); deep learning in a professional environment (Deep Learning); cloud and blockchain technologies (Cloud). The ability to work with big data (BigData) allows you to use the potential of artificial intelligence to accompany the educational, scientific and creative activities of students [6]. Such attempts are being undertaken today by enthusiasts to create robotic programs to prepare for exams in the international arena. Artificial intelligence has also been employed with undergraduate and graduate students of universities as a "consultant" on complex issues that require handling large amounts of data. Deep immersion into a professional environment (Deep Learning) is of particular interest in connection with the development of augmented reality virtual machines (VR), which allow the simulatation of technological processes in a virtual space. The main point is that in this case there is an opportunity to see, feel and evaluate their actions in a professional environment (at the same time, and importantly, without causing possible damage both to yourself and to others). It is likely that a number of previously unexplored educational opportunities will be implemented, allowing us to complement the range of previously known teaching methods. This should be the basis of smart didactics, based on the possibilities of digital technologies in the development of a culture of professional activity. From this point of view, smart didactics is a set of principles, patterns and methods of shaping the student's 
personal and professional success in the educational process based on open dialogical interaction with the teacher, professional and educational environment, intellectual information support systems (artificial intelligence), and internal dialogue, allowing us to stimulate activity in the development of cultural values and the achievement of professionalism.

Cloud technologies (Cloud) provide an opportunity not only to combine information resources but also to simplify their use. The blockchain technology, which has become famous for the proliferation of cryptocurrencies, is actively beginning to be used in foreign universities in the preparation of final qualifying papers. This allows teachers, employers in an open information environment to track student progress in the implementation of the WRC, to assess its promising opportunities for recruiting workers for the company. The blockchain in education is an open self-developing system, where a certain goal (quality specialist training, project execution, personal development, etc.) serves as an order parameter, for which the dialogical active interaction of all participants in the educational process using cloud information space ensures the achievement of the goal.

Now that the era of "electronic textbooks" is over, it is important to understand the opportunities provided by information technologies to substantiate smart-didactics, the use of cloud and blockchain technologies for the development of the entire educational system and the creation of modern conditions for the personal and professional development of a student. The lack of a methodologically sound approach to the introduction of information technology that has been tested in experimental work may impede to the desired successful results. Therefore, the main task of modern research is to enhance the scientific medical, psychological and pedagogical substantiation of the introduction of digital technologies in our lives, starting from the school bench. The currently launched processes of digitalization of education requires careful analysis not only at the level of the implementation of starting dissertation research, but also in the form of a large-scale state project.

Analysis of digital technologies allows us to identify features that give rise to the development of fundamentally new approaches to the organization of the training process, the development of teaching foundations for inclusion in the educational process.

First of all, it should be noted that the use of modern media resources allow us to simultaneously use the word and visualization, and also combine perception with the implementation of certain tasks and exercises, which in the traditional classification of teaching methods (according to the source of information) are represented by different groups of methods. It is possible, not to consider these features, but to relate them to existing methods, however, we can thus not fully use the potential of digital technology. This means that more classification criteria are needed to reflect these features. For example, the nature of the didactic function of digital technology in the educational process; according to the degree of immersion in the virtual educational space, by the nature of the "locus of control" of the student's activity in the educational process (in the educational cloud); going 
beyond the specified boundaries of learning tasks (working with projects in the cloud), etc.

Digital technologies should take a special place in the classification of professional education methods. This is important, first of all, because without understanding the nature of the impact on the personality of a powerful information space, its laws, principles and methods of building work with students, it is impossible to build a policy, strategy, program for such work in the modern digital environment. It is the absence of such scientifically based approaches that led to the formation of an Internet access system for all educational organizations, and there are very few resources for students and teachers. How many of them are needed, what kind, what tasks they have to solve - unfortunately, all this turns out to be hostage to the educational services market. The introduction of a system of restrictions for users and aggregators is not productive. It requires the building of the moral-volitional orientation of young people, which is an important component of personal and professional culture (from an early age, when they pick up a gadget for games).

The introduction of digital technology opens up one important circumstance that has not previously been considered, but due to evolving practice requires discussion in the scientific community. Traditionally, in our educational materials a clear division was made into teaching methods and methods of education. From the standpoint of research and understanding of the laws of these processes, this approach is beyond doubt. That is, an integrative approach is needed to classify the methods of personality formation that would be understandable to the practical teacher. In actual practice, the educational process organically merges with the training, in the work of the teacher, for example, during a lecture, educational and developmental tasks are set. To what extent and how the upbringing and developmental functions can be implemented using digital technologies to develop the personality of the student is not yet completely clear and worked out. In fact, it requires the integration of elements of practical psychology in the activities of the modern teacher. As you know, the most productive studies are at the intersection of sciences and various fields. Therefore the development of an integrative approach in the application of digital technologies for educational purposes is relevant. This is also an important task in the preparation of modern teaching staff. So far, gaming digital technologies developed by programmers reflect the demand of young people and are poorly focused on the development and upbringing of the individual, the formation of the necessary values of civil society and professional culture. We have to admit that the problem of gaming in the professional sphere based on augmented reality (VR) technologies is poorly developed and does not reflect the needs of professional communities.

The substantiation of the essence of smart-didactics, focused on the use of all available means in the development of personality, allows us to use cloud and blockchain technologies in targeted training. Reducing the time of training for a modern bachelor leads to the need for his "targeted" training, which should allow him to more accurately determine the necessary experience in solving professional problems necessary for an employer. The needs of modern companies for qualified 
personnel are not widespread and require purposeful work of an educational organization to train a specialist, a task which can be ensured by using information technologies in the educational process (smart didactics), and by using online platforms for interaction between educational organizations and employers to become real target training based on blockchain technology.

The results of the study and discussion: Digital technologies make it possible to designate an important direction in modern education - the possibilities of smart didactics, which makes it possible to implement "targeted", training of personnel. The development of higher and vocational education based on the use of digital resources allows us to identify this aspect of the interaction of social partners in the training of specialists. The chosen path of economic development, based on the discovery of new talents and their orientation towards the development of innovative technologies, is the main guideline for building a strategy for the development of the modern economy of Uzbekistan, and, consequently, modern educational organizations. That is, effective smart didactics should work for the individual who is able to realize his talent through blockchain technology in the innovative sphere of professional activity.

The key need of many modern start-up projects is that educational organizations produce specialists who possess the core competencies defined by the standards, but they need personnel for specific projects. This is due to the fact that very quickly, there are various information platforms that underlie many innovative products. It is almost impossible to master them all in the modern educational process. Therefore educational organizations choose either popular or accessible platforms. Even the current practice of targeted training does not always take into account the features of future professional activities in the organization of the educational process, since trainees in generalare integrated with other students. Of course, it is not economically beneficial to anyone - neither the state, nor the business, nor the future graduate, who after graduation will have to master his new workplace.

Modern information technologies, based on the ability to implement blockchain, allow us to qualitatively change current practice. Training graduates should be done with clear, understandable guidelines for the student and future employer as a professional function. At the same time, a person can continue education for himself in an informal, second higher or vocational training. Blockchain technology allows us to create requirements for learning organizations, offering them options for targeted training, and creating educational modules for the targeted training of a specific specialist on the basis of a single platform of an educational organization and employers' organizations. Moreover, the requirements may relate to the possession of certain knowledge and experience in solving a certain type of professional task that are not needed by everyone, but are needed by a particular employer who is ready to hire a particular graduate. Moreover, in the blockchain technology, not only an educational organization, but also an employer will be able to see progress in the preparation of a specific specialist. Such technologies have already been implemented and are actively used 
in the logistics system, when using the application to the smartphone we can observe the traffic to the specific stop we need.

Today we can say that the situation with the development of professional standards is far from understanding that they will be completed in the foreseeable future. Their dynamic change is also justified by the introduction of new innovative technologies. The blockchain will provide an opportunity to directly "order" the competencies of graduates for their enterprises. This will also increase the general level of training of all students, since educational organizations will be able to form training modules that can be used for interested students.

Such an understanding of the role of information technology in the development of higher and specialized secondary education clearly meets the current development challenges of the country.

\section{Conclusion}

In conclusion, on the basis of the above, it should be noted that the introduction of digital technologies is very important for the development of a system of higher and specialized secondary education, but it is necessary, simultaneously to develop a scientifically based approach to their implementation. Improving the training based on the cultural approach will allow us to form digital smart didactics, introduce blockchain technology, a process which should become for the basis of the development strategy of modern educational organizations.

Blokchainhas opened up prospects for the development of network forms of interaction between scientific, educational and industrial organizations for the preparation of innovative personnel. A number of aspects look much better in this situation: copyright preservation, prevention of plagiarism, development of innovative products by students in the process of internship and internships, etc.

Our country needs highly professional personnel, so the task of domestic science is not only to transfer the best foreign practices to our conditions, but also to develop a scientifically based advanced educational strategy based on those in the best scientific schools and advanced digital technologies.

\section{References:}

1. Transition 2.0: Digital technologies, higher education, and vision impairment. https://doi.org/10.1016/J.IHEDUC.2017.11.001

2. Digital scholarship, higher education and the future of the public intellectual. https://doi.org/10.1016/j.futures.2018.04.011

3. Блокчейн: уровень и перспективы развития: [Электронный ресурс]. URL:https://bitnovosti.com/2017/03/18/blockchain-state-of-the-art-and prospective/comment-page-1

4. Туракулова С.Т. К вопросу о возможности использования онлайнплатформ для интенсификации обучения в вузах // Молодой ученый. 2017. № 20 .
C.
497-499.
[Электронный
pecypc].

\section{URL:https://moluch.ru/archive/154/43660}

5. Digital-age Learning and Business Engineering Education - a Pilot Study on Students' E-skills. https://doi.org/10.1016/j.promfg.2019.02.320 